\title{
THE ANALYSIS OF THE DRIVING FACTORS OF CHINA'S ECONOMIC GROWTH BASED ON SOLOW MODEL
}

\author{
Xiaoxiao Dong \\ College of Economics and Management, Nanjing \\ University of Aeronautics and Astronautics, Jiangsu 211106, China \\ DOI: 10.46609/IJSSER.2020.v05i02.018 URL: https://doi.org/10.46609/IJSSER.2020.v05i02.018
}

\begin{abstract}
Based on the Solow model and based on time series data from 1995 to 2018, this paper explores the driving factors of China's economic growth and concludes that: (1) There are different trends in the driving effects of capital, labor, and technological progress on economic growth; (2) The factors are ranked in order of the contribution rate to economic growth: Technological progress, Capital, Labor.
\end{abstract}

Keywords: Economic Growth; Solow Model; Driving Factors, Capital; Labor; Technological Progress

\section{INTRODUCTION}

In economics research, economic growth has always been an important topic: on the one hand, measuring the magnitude of economic growth and determining the driving factors of economic growth and the contribution rate of each factor to economic growth are important for the formulation of economic policies. Significance. On the other hand, economic growth will bring about an increase in overall national strength, and enhance the level of people's living standards. Therefore, it is necessary to attach importance to the research of economic growth.

In recent years, with the implementation of reform and opening up policies, the upgrading of industrial structures, and the transformation of economic development methods, China's economic growth has shown a rapid trend, which is mainly reflected in the growth of real GDP. And why does China's economic growth present the current situation? This issue deserves our attention. The purpose of this paper is to explore the driving factors of China's economic growth in recent years, and to provide some suggestions for China's current economic policy making based on the conclusions. 


\section{International Journal of Social Science and Economic Research}

ISSN: $2455-8834$

Volume: 05, Issue: 02 "February 2020"

The economic model selected in this paper is the Solow model, and our all research is based on the assumptions of the Solow model. The chapter arrangement of this paper is as follows: The second chapter contains review of relevant literature and model introduction; The third chapter includes parameter estimation and testing of the model; The main content of the forth chapter is the calculation and analysis of the contribution rate of each driving factor; The fifth chapter provides research conclusion and policy recommendations.

\section{RELEVANT LITERATURE REVIEW AND MODEL INTRODUTION}

\subsection{Literature review}

Scholars at home and abroad have done a lot of research on the topic of economic growth based on different perspectives:

From the perspective of space economics, some scholars thought that location is an important factor affecting economic growth. Walz (1993) held the opinion that the integration of regional economy can promote the regional concentration of innovative products. Not only that, the concentration of industrial sectors can boost the increase of productivity, thereby promoting regional economic growth ${ }^{[1]}$. Based on the assumption that capital is completely illiquid, Baldwin (1998) dynamicized the new economic geographic model and established a capital creation model, concluding that economics growth and the geographical location are interrelated $^{[2]}$. Sun and Ye (2011) used the panel data of Chinese cities to explore the relations between resource dependence, geographical location, and urban economic growth in China, and further concluded that geographical location and natural resource dependence have a significant joint impact on economic growth, and the superior geographical location can reduce the "resource curse" effect brought by the dependence of natural resources, that is, the economic growth potential and the superiority of the geographical location are positively correlated ${ }^{[3]}$. Jiang and Gao (2012) established the model of space economics and concluded that the intellectual capital stocks in different locations are different, and the absorption capacity of knowledge in each location is also different, which makes the regional knowledge spillover appear asymmetric characteristics and then leads to differences in the long-term economic growth rate of different locations ${ }^{[4]}$.

Some scholars sought the driving factors of economic growth based on the perspective of international trade. Ghali (1976) held the opinion that export trade plays an important role in the economic growth for developing countries. He selected the data of Philippines from 1953 to 1970 and classified exports into tourism exports and other products and services exports, and explored the impact of these two exports on economic growth, then drew the conclusion that tourism exports play an important role in promoting the economic growth of Philippines ${ }^{[5]}$. 


\section{International Journal of Social Science and Economic Research}

ISSN: $2455-8834$

Volume: 05, Issue: 02 "February 2020"

Young (1991) analyzed the relationship between trade and economic growth, and thought that free trade makes developing countries with abundant labor have greater economic growth potential than developed countries ${ }^{[6]}$. Based on the time series data of China from 1980 to1998, Liu (2001) explored the relationship between the growth rate of GDP and foreign trade and concluded that imports can promote economic growth, but economic growth and exports show a weak correlation $^{[7]}$. Huang et al (2014) selected cross-section data of 286 cities in China, and researched the relationships between geographical location, international trade and economic growth, concluding that international trade has a significant positive effect on China's urban per capita income, which means that an increase in international trade volume can promote economic $\operatorname{growth}^{[8]}$.

The research on economic growth based on production factors (factors include technical inputs) is also quite rich: By establishing a knowledge spillover model, Romer (1986) thought that technological progress is the sole source of economic growth ${ }^{[9]}$. Pakko (2002) calculated the real investment and price index of the United States from 1954 to 2001 by using the chain weighting method, and based on this research, he concluded that capital-embodied technological progress of U.S can explain $60 \%-68 \%$ of potential economic growth, and the impact of capital-embodied technological progress on economic growth is different at different stages ${ }^{[10]}$. Through mathematical analysis, quantitative analysis, and statistical analysis, Ye (2003) put forward his point of view that the increase in production factors, technological progress, and institutional innovation are all important driving factors for the long-term economic growth trend of China ${ }^{[11]}$. Guo (2005) analyzed the driving factors of China's economic growth based on the revised Solow model, and thought that changes in the economic structure (changes in the structure of labor and capital would affect economic growth ${ }^{[12]}$. Fan (2010) used the Solow model as the basis of the model and selected time series data from 1978 to 2008 to seek the driving factors of China's economic growth. After research, the results obtained are as follows: the impact of labor on economic growth is not prominent, and the impact of capital on economic growth is significant ${ }^{[13]}$. Establishing the Cobb-Douglas function, Luan and Ouyang (2012) used panel data from 31 provinces and cities in China from 1997 to 2009 to analyze the relationship between capital, labor, other inputs and economic growth, and concluded that China's economic growth has mainly benefited from investment in addition to technological progress in recent years ${ }^{[14]}$. Zhang (2012) took Solow growth model as the model basis and selected macro data from the western region of China from 1995 to 2010, and drew a conclusion through empirical analysis: physical capital plays a strong role in promoting economic growth in the western region, while the effect of human capital on economic growth is relatively weak ${ }^{[15]}$. Constructing an expanded Solow model, Li and Xia (2013) introduced the comprehensive stock of human capital into the Solow model, and found through empirical analysis that human capital and technological progress have gradually become the main factors affecting China's economic growth., and the 


\section{International Journal of Social Science and Economic Research}

ISSN: $2455-8834$

Volume: 05, Issue: 02 "February 2020"

impact of labor force on economic growth is Gradually weakened ${ }^{[16]}$. Liu (2013) selected Chinese inter-provincial data from 1989 to 2010 to analyze the sources of economic growth in China in whole and in various regions, and the results showed that production factors are the most important factors for economic growth $^{[17]}$. Jin and Zhou (2013) established a system coupling model between human capital and economic growth based on the system coupling theory, measured the characteristics of the coupling change between human capital and economic growth, and drew a conclusion: the coupling degree of human capital and economic growth in all provinces in China has been at a low level, and it shows a decreasing trend from east to west, which means that the interaction between human capital and economic growth in the eastern region is stronger than in the western region ${ }^{[18]}$. Li and Liu (2015) combined the directional distance function with the additive characteristics of the Luenbeger indicator to study the spatiotemporal laws, source factors, and dynamic evolution of China's regional economic growth performance from 1985 to 2015 . Based on these, they concluded that labor is the most important factor that promotes economic growth performance and the cumulative growth rate of total factor labor productivity is higher than capital and energy ${ }^{[19]}$.

It is worth noting that this article uses the Solow model to study the driving factors of economic growth, and explores the topic of economic growth from the perspective of various factor inputs. Therefore, we need to pay more attention to the analysis of economic growth based on production factors (including technology inputs).

\subsection{Model introduction}

The economic model selected in this article is the Solow model. This section will introduce the model and provide a theoretical basis for the empirical and calculation.

In 1928, an economist named Douglas and a mathematician named Cobb in U.S researched economic production on the basis of summing up the previous theoretical results, and concluded that among all production inputs, capital and labor are the most important factor inputs, which means capital and labor are also the most important drivers of economic growth. Based on this, they proposed the famous Cobb-Douglas production function (C-D production function), and the specific form of the function is as follows:

$Y=A(t) K^{\alpha} L^{\beta} \mu$

In the function (1), $\mathrm{Y}$ represents output, $\mathrm{t}$ represents time, $\mathrm{A}(\mathrm{t})$ represents comprehensive technical level, $\mathrm{K}$ represents capital investment input, and $\mathrm{L}$ represents labor input, $\alpha$ indicates the output elasticity of capital, $\beta$ indicates the output elasticity of labor, and the values of $\alpha$ and $\beta$ are both in the range of $[0,1] . \mu$ is a random interference term. If $\alpha+\beta<1$, the returns to scale 
decrease; If $\alpha+\beta=1$, the returns to scale don't change; If $\alpha+\beta>1$, the returns to scale increases. Limited to the production conditions at the time, they did not consider technology as an important input factor, then they thought that $\mathrm{A}(\mathrm{t})$ is generally constant in the short term, and generally speaking, the larger A (t), the higher the level of technology or production management.

In 1957, based on the C-D production function, Solow introduced technological progress into the production function, and constructed the Hicks neutral technology progression function:

$Y=A(t) F(K, L)$

The specific form of function is as follows:

$Y=A_{0} e^{\lambda T} K^{\alpha} L^{\beta} \mu$

In the function (3), $\mathrm{A}_{0}$ is the constant initial technical level, $\mathrm{e}$ is the base of natural logarithm, $\lambda$ is the technological progress rate, $\mathrm{K}$ represents capital investment input, and $\mathrm{L}$ represents labor input, T represents time, $\alpha$ and $\beta$ are the output elasticities of capital and labor, and $\mu$ is the random interference term. It is worth noting that in the Solow model, a key assumption of the production function is that returns to scale of capital and labor are constant, which is reflected in the model as $\alpha+\beta=1$. Taking the logarithm of this function, we get the following result:

$$
\ln Y=\ln \left(A_{0}\right)+\lambda T+\alpha \ln K+\beta \ln L+\ln \mu
$$

We round off the random interference term in the function (4) and calculate the derivative of T on both the left and right sides of the function (4). The result is as follows:

$$
(d Y / d T) *(1 / Y)=\lambda+\alpha *(d K / d T) *(1 / K)+\beta *(d L / d T) *(1 / L)
$$

On the one hand, because economic data does not have continuity, the differential can be replaced by differential; On the other hand, $d T=1$. Therefore, The formula further becomes the following form:

$\Delta Y / Y=\lambda+\alpha^{*}(\Delta K / K)+\beta^{*}(\Delta L / L)$

Assuming $y=\Delta Y / Y, k=\Delta K / K$, and $l=\Delta L / L$, we can get the result of

$y=\lambda+\alpha k+\beta l$ 
International Journal of Social Science and Economic Research

ISSN: $2455-8834$

Volume: 05, Issue: 02 "February 2020"

The formula (7) is called the Solow growth rate equation, and shows that the driving factors for economic growth are the rate of technological progress, capital and labor. According to formula (7), the value of $\lambda$ can be calculated. This method is called Solow residual method.

Based on the Solow model, the function (4) can be constructed. Using $\beta=1-\alpha$, the function (4) is transformed into

$$
\ln Y=\ln \left(A_{0}\right)+\lambda T+\alpha \ln K+(1-\alpha) \ln L+\ln \mu
$$

And the function (8) can be further transformed into

$$
\ln (Y / L)=\ln \left(A_{0}\right)+\lambda T+\alpha \ln (K / L)+\ln \mu
$$

Based on the data of output, labor, capital, and time, using eviews8.0, we can calculate the estimated value of $\alpha$, and derive the estimated value of $\beta$, then calculate the estimated value of $\lambda$ according to the formula (7). knowing specific calculation results, we can determine the degree of impact of capital, labor, and technological progress on economic growth, the specific method is to calculate the contribution rates of the three driving factors of capital, labor, and technological progress to economic growth..

\section{PARAMETRE ESTIMATION AND TESTING OF MODEL}

\subsection{Parameter Estimation Of Model}

From Section 2.2, the model to be constructed in this paper is function (9). According to the form of model, the required variables are output (Y), capital input (K), labor input (L) and time variable $(\mathrm{T})$. With reference to previous literature, the GDP can be regarded as output, the fixed asset investment in the whole society as capital input, and the number of employed persons as labor input.

According to the variables required by the model, time series data from 1995 to 2016 of China are used as sample data. It should be noted that because the study is about economic growth, the price factor must be eliminated when dealing with data on GDP and the fixed asset investment in the whole society. Therefore, the following data are measured in 1995 prices. The following data are measured at 1995 price levels, that is, $\mathrm{Y}$ is the constant-price GDP calculated from the GDP index, and $\mathrm{K}$ is the constant-price fixed asset investment calculated from the fixed asset price index. Taking 1995 as the base period for this study means that in 1995, T =0, and as the year increases by 1 , the value of $\mathrm{T}$ increases by 1 . The specific data of $\mathrm{Y}, \mathrm{K}, \mathrm{L}$ and $\mathrm{T}$ and the calculated values of $\mathrm{Y} / \mathrm{L}$ and $\mathrm{K} / \mathrm{L}$ are shown in the following table 1 (initial data source: " China Statistical Yearbook"): 
International Journal of Social Science and Economic Research

ISSN: $2455-8834$

Volume: 05, Issue: 02 "February 2020"

Table 1: The Data Of Variables

\begin{tabular}{|c|c|c|c|c|c|c|}
\hline Year & $\begin{array}{c}\mathrm{Y}\left(1 * 10^{8}\right. \\
\text { yuan })\end{array}$ & $\mathrm{T}$ & $\begin{array}{c}\mathrm{K}\left(1 * 10^{8}\right. \\
\text { yuan })\end{array}$ & $\begin{array}{c}\mathrm{L}\left(1 * 10^{5}\right. \\
\text { people })\end{array}$ & $\mathrm{Y} / \mathrm{L}$ & $\mathrm{K} / \mathrm{L}$ \\
\hline 1995 & 61339.9 & 0 & 20019.3 & 68065 & 0.9012 & 0.2941 \\
\hline 1996 & 67412.5501 & 1 & 22032.2115 & 68950 & 0.9777 & 0.3195 \\
\hline 1997 & 73614.5047 & 2 & 23580.9508 & 69820 & 1.0543 & 0.3377 \\
\hline 1998 & 79356.4361 & 3 & 26910.9052 & 70637 & 1.1234 & 0.381 \\
\hline 1999 & 85466.8817 & 4 & 28396.7436 & 71394 & 1.1971 & 0.3977 \\
\hline 2000 & 92731.5666 & 5 & 30969.4973 & 72085 & 1.2864 & 0.4296 \\
\hline 2001 & 100428.2866 & 6 & 34871.5682 & 72797 & 1.3796 & 0.479 \\
\hline 2002 & 109567.2607 & 7 & 40680.9885 & 73280 & 1.4952 & 0.5551 \\
\hline 2003 & 120523.9868 & 8 & 50847.0974 & 73736 & 1.6345 & 0.6896 \\
\hline 2004 & 132696.9094 & 9 & 61071.4594 & 74264 & 1.7868 & 0.8224 \\
\hline 2005 & 147824.3571 & 10 & 75714.411 & 74764 & 1.9772 & 1.0127 \\
\hline 2006 & 166598.0505 & 11 & 92430.2765 & 74978 & 2.222 & 1.2328 \\
\hline 2007 & 190254.9736 & 12 & 111060.4056 & 75321 & 2.5259 & 1.4745 \\
\hline 2008 & 208709.7061 & 13 & 128351.3249 & 75564 & 2.762 & 1.6986 \\
\hline 2009 & 228328.4185 & 14 & 170900.39 & 75828 & 3.0111 & 2.2538 \\
\hline 2010 & 252531.2308 & 15 & 184854.8868 & 76105 & 3.3182 & 2.4289 \\
\hline 2011 & 276521.6977 & 16 & 214612.8618 & 76420 & 3.6184 & 2.8083 \\
\hline 2012 & 298366.9119 & 17 & 255355.2924 & 76704 & 3.8898 & 3.3291 \\
\hline 2013 & 321639.531 & 18 & 303240.7246 & 76977 & 4.1784 & 3.9394 \\
\hline 2014 & 345119.2167 & 19 & 346168.7322 & 77253 & 4.4674 & 4.481 \\
\hline 2015 & 368932.4427 & 20 & 386923.3967 & 77451 & 4.7634 & 4.9957 \\
\hline 2016 & 393650.9164 & 21 & 420057.4482 & 77603 & 5.0726 & 5.4129 \\
\hline 2017 & 420419.1787 & 22 & 419793.8091 & 77640 & 5.415 & 5.4069 \\
\hline 2018 & 448166.8445 & 23 & 401042.26 & 77586 & 5.7764 & 5.169 \\
\hline & & & & & & \\
\hline
\end{tabular}

Table 1 provides time series data of $\mathrm{Y} / \mathrm{L}, \mathrm{K} / \mathrm{L}$, and $\mathrm{T}$. The values of $\ln \mathrm{A}_{0}$ (constant terms), $\lambda$, and $\alpha$ can be estimated by the least square method. The software used in this article is Eviews 8.0. We input variables data into Eviews 8.0, and then we can get the specific estimation results of various parameters and other indicators of the model. The specific results of the model are shown in the following table 2. 
International Journal of Social Science and Economic Research

ISSN: 2455-8834

Volume: 05, Issue: 02 "February 2020"

Table 2: The Results Of The Model

\begin{tabular}{|c|c|c|c|}
\hline Variables & $\ln \mathrm{A}_{0}$ & $\mathrm{~T}$ & $\ln (\mathrm{K} / \mathrm{L})$ \\
\hline Coefficient estimation & 0.246743 & 0.045307 & 0.271838 \\
\hline t-statistic & 5.344974 & 9.554700 & 8.507651 \\
\hline R-squared & \multicolumn{3}{|c|}{0.998904} \\
\hline Adjusted R-squared & \multicolumn{3}{|c|}{0.998800} \\
\hline F-statistic & 9571.943 \\
\hline
\end{tabular}

From the table 2 , we can get the results of coefficient estimates for each parameter: $\ln \mathrm{A} 0=0.246743, \lambda=0.045307$, and $\alpha=0.271838$. so $\beta=1-\alpha=0.728162$. The estimated result of the model is

$$
\ln (Y / L)=0.246743+0.045307 T+0.271838 \ln (K / L)+\ln \mu
$$

where $\ln \mu$ is the random interference term.

\subsection{Testing Of Model}

\section{(1) Economic significance test}

According to the requirements of the model, when $\alpha$ and $\beta$ are located at $[0,1]$, and $A_{0}>0$, the model is in economic significance. On the one hand, $\alpha=0.271838$ and $\beta=0.728162$, which are all located at $[0,1]$; On the other hand, $\ln \mathrm{A}_{0}=0.246743$, we know that $\mathrm{A}_{0}>0$. So the model can be tested for economic significance.

\section{(2) Statistical significance test}

The determination coefficient of the equation is 0.998904 , and the adjusted determination coefficient is 0.998800 , which are all very close to 1 , indicating that the overall fitting level between the sample regression line represented by the model and the sample observations is high, so the equation can pass goodness of fit test.

With a significance level of $0.05, \mathrm{~F}_{0.05}(2,21)=3.49$. the F-statistic of the model is 9571.943 which is higher than $\mathrm{F}_{0.05}(2,21)$. It shows that the linear relationship of this model is significant at $95 \%$ confidence level, which means that the model can pass the significance test of overall linearity. 
With a significance level of $0.05, \mathrm{t}_{0.025}(21)=2.080$. The $\mathrm{t}$ statistics of the variable $\mathrm{T}$ and the variable $\ln (\mathrm{K} / \mathrm{L})$ are 9.554700 and 8.507651 , and the $t$ statistic of the constant term is 5.344974, which are all higher than $\mathrm{t}_{0.025}(21)$, indicating that at $95 \%$ confidence level, the effects of the $\mathrm{T}$, $\ln (\mathrm{K} / \mathrm{L})$ and constant term are significant, that is, all variables of the model can pass the significance test of the variables.

In summary, the model can pass statistical significance test.

\subsection{Econometric significance test}

A multicollinearity test is performed on the variables $\mathrm{T}$ and $\ln (\mathrm{K} / \mathrm{L})$ in the model, and it is found that the correlation coefficient between the two variables is 0.991479 , which shows that there is a high degree of multiple correlation between the two variables. We need to realize that the economy has been showing an upward trend in recent years. As the year increases, $\mathrm{K} / \mathrm{L}$ shows an increasing trend, and $\ln (\mathrm{K} / \mathrm{L})$ naturally shows an increasing trend. In order to ensure the integrity and practical applicability of the model, even if there is a high correlation between the variables, we must retain these two variables, and we cannot use the stepwise regression method to eliminate any one variable.

We use the Lagrange multiplier method to test the serial correlation in the model, and then find that there is indeed a serial correlation in the model. So we use the Cochrane-Octor iteration method to modify the model, but the result of the correction is not reasonable. Therefore, in order to ensure the overall validity of the model, the Cochrane-Octor iteration method is no longer used to modify the serial correlation of the model.

Although the general research based on time series data does not have the problem of heteroscedasticity, in order to be rigorous, we still perform heteroscedasticity test on the model. The test of heteroscedasticity used in this paper is the White test. After testing, the auxiliary regression equation is not significant, so the model has no heteroscedasticity.

Therefore, the final form of the model is function (10), and the model can also be expressed as

$$
Y=e^{0.246743} e^{0.045307 T} K^{0.271838} L^{0.728162}
$$

\section{CALCULATION AND ANALYSIS OF CONTRIBUTION RATE OF EACH FACTOR}

\subsection{Calculation Of Contribution Rate Of Each Factor}




\section{International Journal of Social Science and Economic Research}

ISSN: $2455-8834$

Volume: 05, Issue: 02 "February 2020"

In order to determine the contribution rate of various factors to economic growth, we must first calculate the average growth rate of GDP, the fixed asset investment in the whole society and employment, and further calculate the rate of technological progress. This article uses the geometric average method to calculate the average growth rate of each factor, and the specific formulas are as follows:

$$
\begin{aligned}
& y=\left[\left(Y_{T} / Y_{0}\right)^{1 / T}-1\right]^{* 100 \%} \\
& k=\left[\left(K_{T} / K_{0}\right)^{1 / T}-1\right] * 100 \% \\
& l=\left[\left(L_{T} / L_{0}\right)^{1 / T}-1\right] * 100 \%
\end{aligned}
$$

In the formulas, $\mathrm{y}, \mathrm{k}$, and 1 represent the average growth rates of $\mathrm{Y}, \mathrm{K}$, and $\mathrm{L}$ respectively. $\mathrm{Y}_{\mathrm{T}}$, $\mathrm{K}_{\mathrm{T}}$, and $\mathrm{L}_{\mathrm{T}}$ are the values of the current period, and $\mathrm{Y}_{0}, \mathrm{~K}_{0}$, and $\mathrm{L}_{0}$ are the values of the base period (the values in 1995). We calculate $\mathrm{y}(\%), \mathrm{k}(\%)$, and $1(\%)$ from 1996 to 2016 according to the formula (12), (13) and (14), and then calculate the technological progress rate $\lambda(\%)$ based on the formula (7). The calculation results are shown in table 3.

Table 3: The Average Growth Rate Of Each Factor

\begin{tabular}{|c|c|c|c|c|}
\hline Year & $\mathrm{y}(\%)$ & $\mathrm{k}(\%)$ & $1(\%)$ & $\lambda(\%)$ \\
\hline 1996 & 9.9 & 10.0549 & 1.3002 & 6.2199 \\
\hline 1997 & 9.5494 & 8.5316 & 1.281 & 6.2974 \\
\hline 1998 & 8.9632 & 10.3638 & 1.244 & 5.24 \\
\hline 1999 & 8.646 & 9.1327 & 1.2009 & 5.2889 \\
\hline 2000 & 8.5955 & 9.1182 & 1.1543 & 5.2764 \\
\hline 2001 & 8.5462 & 9.6909 & 1.1265 & 5.0916 \\
\hline 2002 & 8.6252 & 10.6603 & 1.0602 & 4.9553 \\
\hline 2003 & 8.7961 & 12.3575 & 1.0054 & 4.7048 \\
\hline 2004 & 8.9402 & 13.1934 & 0.9732 & 4.6451 \\
\hline 2005 & 9.1837 & 14.2281 & 0.9432 & 4.6292 \\
\hline 2006 & 9.4988 & 14.9203 & 0.8833 & 4.7997 \\
\hline 2007 & 9.883 & 15.3478 & 0.8477 & 5.0937 \\
\hline 2008 & 9.869 & 15.3648 & 0.8072 & 5.1044 \\
\hline 2009 & 9.8354 & 16.5523 & 0.7744 & 4.7719 \\
\hline 2010 & 9.8862 & 15.9735 & 0.7471 & 5 \\
\hline 2011 & 9.862 & 15.9813 & 0.7263 & 4.9889 \\
\hline 2012 & 9.7456 & 16.1558 & 0.7054 & 4.8402 \\
\hline 2013 & 9.6366 & 16.2986 & 0.6859 & 4.7066 \\
\hline 2014 & 9.5124 & 16.1848 & 0.6687 & 4.6258 \\
\hline 2015 & 9.3803 & 15.9602 & 0.648 & 4.5698 \\
\hline
\end{tabular}


International Journal of Social Science and Economic Research

ISSN: $2455-8834$

Volume: 05, Issue: 02 "February 2020"

\begin{tabular}{|c|c|c|c|c|}
\hline 2016 & 9.2511 & 15.5968 & 0.6264 & 4.5552 \\
\hline 2017 & 9.1385 & 14.8344 & 0.6001 & 4.669 \\
\hline 2018 & 9.0269 & 13.9193 & 0.5709 & 4.8274 \\
\hline
\end{tabular}

According to the table 3, the average economic growth rate of China was between $8 \%$ and $10 \%$ from 1996 to 2016, which has been maintained at a relatively stable level. The average growth rate of capital was between $8 \%$ and $14 \%$ from 1996 to 2004, and since 2005, the average growth rate of capital is higher than $14 \%$, but not more than $17 \%$; The growth rate of labor is relatively low, and it shows a downward trend in general. The average growth rate of labor was $1.30 \%$ in 1996 , and by 2018 , the average growth rate of labor has decreased to $0.5709 \%$. The rate of technological progress showed a downward trend from 1996 to 2000, but the degree of decrease was small. Since 2001, the rate of technological progress has been maintained at $4 \%$ to $5 \%$.

Based on the average growth rate of the economy, capital and labor, and the rate of technological progress, we can measure the contribution rate of each factor to economic growth. The contribution rate of capital to economic growth, the contribution rate of labor to economic growth, and the contribution rate of technological progress to economic growth are as follows:

$E_{k}=\left(\alpha^{*} k / y\right) * 100 \%$

$E_{l}=(\beta * l / y) * 100 \%$

$E_{\lambda}=(\lambda / y) * 100 \%$

According to formulas (15), (16) and (17), we calculate the contribution rate of capital, labor, and technological progress to economic growth from 1996 to 2018. The results are shown in the table 4.

Table 4: The Contribution Rate Of Capital, Labor, And Technological Progress To Economic Growth

\begin{tabular}{|c|c|c|c|}
\hline Year & $\begin{array}{c}\text { Contribution Rate Of } \\
\text { Capital }\end{array}$ & $\begin{array}{c}\text { Contribution Rate Of } \\
\text { Labor }\end{array}$ & $\begin{array}{c}\text { Contribution Rate Of } \\
\text { Technological Progress }\end{array}$ \\
\hline 1996 & 27.61 & 9.56 & 62.83 \\
\hline 1997 & 24.29 & 9.77 & 65.94 \\
\hline 1998 & 31.43 & 10.11 & 58.46 \\
\hline 1999 & 28.71 & 10.12 & 61.17 \\
\hline 2000 & 28.84 & 9.78 & 61.38 \\
\hline 2001 & 30.82 & 9.6 & 59.58 \\
\hline 2002 & 33.6 & 8.95 & 57.45 \\
\hline 2003 & 38.19 & 8.32 & 53.49 \\
\hline
\end{tabular}


International Journal of Social Science and Economic Research

ISSN: $2455-8834$

Volume: 05, Issue: 02 "February 2020"

\begin{tabular}{|l|c|c|c|}
\hline 2004 & 40.11 & 7.93 & 51.96 \\
\hline 2005 & 42.11 & 7.48 & 50.41 \\
\hline 2006 & 42.7 & 6.77 & 50.53 \\
\hline 2007 & 42.21 & 6.25 & 51.54 \\
\hline 2008 & 42.32 & 5.96 & 51.72 \\
\hline 2009 & 45.75 & 5.73 & 48.52 \\
\hline 2010 & 43.92 & 5.5 & 50.58 \\
\hline 2011 & 44.05 & 5.36 & 50.59 \\
\hline 2012 & 45.06 & 5.27 & 49.67 \\
\hline 2013 & 45.98 & 5.18 & 48.84 \\
\hline 2014 & 46.25 & 5.12 & 48.63 \\
\hline 2015 & 46.25 & 5.03 & 48.72 \\
\hline 2016 & 45.83 & 4.93 & 49.24 \\
\hline 2017 & 44.13 & 4.78 & 51.09 \\
\hline 2018 & 41.92 & 4.6 & 53.48 \\
\hline
\end{tabular}

\subsection{Analysis Of Contribution Rate Of Each Factor}

From the previous section, we can know the contribution rate of capital, labor, and technological progress to economic growth from 1996 to 2018. Based on this, we can make the following analysis:

We use the arithmetic mean method to calculate the average contribution rate of capital, labor, and technological progress to economic growth from 1996 to 2018, and the result is that the average contribution rate of capital to economic growth is $39.22 \%$, and the average contribution rate of labor to economic growth is $7.05 \%$, the contribution rate of technological progress to economic growth is $53.73 \%$. From this perspective, the contribution rate of technological progress to economic growth is the highest, the contribution rate of capital to economic growth is only lower than the contribution rate of technological progress to economic growth, and the contribution rate of labor to economic growth is the lowest. However, it should be noted that regardless of the change trend of each factor, simply calculating the arithmetic average of the contribution rate of each factor in sample period is not of strong reference for forecasting the future situation.

From the vertical perspective of the changes in the contribution rate of various factors to economic growth, the contribution rate of capital to economic growth showed an increasing trend from 1996 to 2015, while the contribution rate of capital to economic growth gradually decreased year by year from 2016 to 2018; The contribution rate of labor to economic growth showed a decreasing trend from 1996 to 2018; The contribution rate of technological progress to 


\section{International Journal of Social Science and Economic Research}

ISSN: $2455-8834$

Volume: 05, Issue: 02 "February 2020"

economic growth showed an decreasing trend from 1996 to 2014, while the contribution rate of technological progress to economic growth gradually increased year by year from 2015 to 2018 .

From the horizontal perspective of the contribution rate of various factors to economic growth each year, the contribution rate of labor to economic growth is the lowest, while the contribution rate of capital and technological progress to economic growth has always occupied a large share. It can be found through observation that the contribution rate of capital to economic growth is lower than the contribution rate of technological progress to economic growth.

Based on the above analysis, we can know that from the perspective of the average contribution rate of each factor, it can be concluded that technological progress is the most important factor to promote economic growth in the sample period. And if we take into account the changes in the contribution rate of each factor during the sample period and the changes in the proportion of each factor's contribution to economic growth at different time periods, it should be concluded that during each year of the sample period, the most important factor contributing to economic growth is technological progress, while the lowest contributing factor is labor.

\section{RESEARCH CONCLUSION AND POLICY SUGGESTIONS}

\subsection{Research Conclusion}

In this paper we build a Solow model based on time series data of China from 1995 to 2018, and then estimate parameters of the model with the least square method. The final result of the model is function (11), and it shows that under the assumption of constant return of scale in the Solow model, the output elasticity of capital is much lower than that of labor.

After performing relevant calculations on the sample data, we know that, on the one hand, the average growth rate of economic output is at a level of about 9\%, which shows that Chinese economy has maintained steady and rapid growth. In terms of factors of production, the average growth rate of capital has been at a relatively high level, while the average growth rate of labor has been at a relatively low level; On the other hand, the annual technological progress rate calculated based on the average growth rates of economic output, capital input, and labor input shows that although the level of technological progress in China has shown a slight downward trend, it has remained basically stable.

Based on the economic output, the average growth rate of capital, the average growth rate of capital labor and the rate of technological progress, the contribution rate of capital, labor, and technological progress to economic growth has also been calculated. Based on this, the important conclusion of this article is drawn: (1) The change trends in the effects of capital, labor, and technological progress on economic growth are different; (2) Technological progress is the most 


\section{International Journal of Social Science and Economic Research}

ISSN: $2455-8834$

Volume: 05, Issue: 02 "February 2020"

important driving factor for economic growth. Secondly, capital also makes a relatively large contribution to economic growth. Finally, labor makes the smallest contribution to economic growth.

\subsection{Policy Suggestions}

According to the research conclusions in this article, we can put forward some policy suggestions for the government from the perspective of promoting the steady and healthy growth of our economy, as follows:

First of all, we are concerned that technological progress is the most important driving factor for economic growth. Therefore, in order to promote stable economic growth, the government needs to increase the rate of technological progress to improve the contribution of technological progress to economic growth. The specific measures that can be taken are: Increasing the funding for scientific and technological development; Encouraging scientific research and innovation in universities and other scientific research institutions; Developing new technologies; Increasing the salary of scientific researchers to attract more talents.

Secondly, the research results show that capital is also the main driving factor for economic growth. Therefore, the government needs to continue to encourage investment to increase the amount of capital. The specific measures that can be taken include: Reducing or exempting some corporate taxes to support for venture capital enterprises; Reducing interest rates to reduce corporate borrowing costs; Expanding corporate financing channels.

Finally, the contribution rate of labor to economic growth is the lowest, so the government needs to adopt employment promotion policies to increase the growth rate of labor, further improve the contribution of labor to economic growth, and increase the momentum of economic development. The specific measures include: Improving relevant laws and regulations to protect the legitimate rights and interests of employees; Creating a fair employment environment and eliminating invisible discrimination in the job market; Increasing public financial investment in promoting employment, and organizing more vocational skills training activities; Encouraging the development of new industries to increase employment.

\section{REFERENCES}

[1] Walz U. Transport costs, intermediate goods, and localized growth[J]. Regional Science \& Urban Economics, 1993, 26(6):671-695.

[2] Baldwin R E. Agglomeration and endogenous capital[J]. Social Science Electronic Publishing, 1998, 43(2):253-280. 
International Journal of Social Science and Economic Research

ISSN: $2455-8834$

Volume: 05, Issue: 02 "February 2020"

[3] Yong-Ping S , Chu-Sheng Y E . Resource Dependence, Geographical Location and Urban Economic Growth[J]. Modern Economic Science, 2011.

[4] Fuxin J , Lina G . The Asymmetry of Interregional Knowledge Spillovers, Location of Industry and Endogenous Economic Growth[J]. Finance \& Trade Economics, 2012.

[5] Ghali M A. Tourism and Economic Growth: An Empirical Study[J]. Economic Development \& Cultural Change, 1976, 24(3):527-538.

[6] Young A. Learning by Doing and the Dynamic Effects of International Trade[J]. Quarterly Journal of Economics, 1991, 106(2):369-405.

[7] Xiaopeng L . A Positive Analysis on Our Import-export Increase and Economic Growth[J]. Modern Economic Science, 2001.

[8] Xin-Fei H , Yuan-Jian L I, Yong-Ru Z . Geographical Factors, International Trade and Economic Growth: An Empirical Cross-section Analysis Based on Data of China's 286 Prefecture and Above Leveled Cities[J]. Journal of International Trade, 2014.

[9] Romer P M. Increasing Returns and Long-Run Growth[J]. Journal of Political Economy, 1986, 94(5):1002-1037.

[10] Pakko M R. Investment-specific technology growth: concepts and recent estimates[J]. Review, 2002, 84(vember):37-48.

[11] Feiwen Y. Factor Input and China's Economic Growth [D]. Xiamen University, 2003:230-233.

[12] Lei G . The Possibility Of the Economic Growth: An Estimation Based on Modified Solow Model[J]. Modern Economic Science, 2005.

[13] Ying F. An Empirical Analysis of China's Economic Growth in the 30 Years of Reform and Opening Up Based on the Solow Model[J]. Modern Business Trade Industry, 2010, 22(21):34-34.

[14] Dapeng Luan, Rihui OY. Internal Input Structure of Production Factors and China's Economic Growth[J]. The Journal of World Economy, 2012(6):78-92.

[15] Lin Z. The Contribution of Human Capital and Material Capital to Economic Growth in the Western Regions: A Solow Model Test Based on the Data of the Western Regions from 1995 to 2010[J]. Hunan Social Sciences, 2012(3):132-135. 
[16] De-Huang Li, En-Jun Xia . Research on the Influence of Human Capital on China Economy Growth Based on Extended Solow Model[J]. China Population Resources \& Environment, 2013.

[17] Ruixiang L. Exploring the Source of China's Economic Growth: Factor Input, Productivity and Environmental Consumption[J]. The Journal of World Economy, 2013(10):123-141.

[18] Jin L, Huimin Z. Empirical Analysis of Coupling Relationship between Human Capital and Economic Growth in Chinese Provinces[J]. Journal of Quantitative \& Technical Economics, 2013.

[19] Lanbing L , Binglian L. Source Identification and Dynamic Evolution of Regional Economic Growth Performance in China: Based on Input-Level Decomposition[J]. Economic Research Journal, 2015. 